\title{
Course and distribution of facial corticobulbar tract fibres in the lower brain stem
}

\author{
S Terao, N Miura, A Takeda, A Takahashi, T Mitsuma, G Sobue
}

Division of Neurology, Fourth Department of Internal Medicine, Aichi Medical University, Nagakute, Aichi 480-1195, Japan $S$ Terao

N Miura

T Mitsuma

Shizuoka National Hospital, Shizuoka, Japan

A Takeda

Tokai Central

Hospital,

Kakamigahara, Gifu, Japan

A Takahashi

Department of Neurology, Nagoya University School of Medicine, Nagoya,

Japan

G Sobue

Correspondence to: Dr Shin-ichi Terao

102949@

gk.amu.aichi-med-u.ac.jp

Received 2 December 1999 and in revised form

13 March 2000

Accepted 23 March 2000

\begin{abstract}
The course and distribution of the facial corticobulbar tract (CBT) was examined by correlating MRI of brain stem lesions with neurological symptoms and signs including central (C-FP) or peripheral facial paresis (P-FP) in 70 patients with localised infarction of the lower brain stem. C-FP occurred more often in patients with lesions of the lower pons or upper medulla of the ventromedial brain stem. Some patients with dorsolateral infarcts of the upper medulla to the lower pons showed C-FP, mostly on the lesion side. P-FP on the side of the lesion was also seen in patients with dorsolateral involvement of the lower pons. Patients with ventromedial infarction of the brain stem showed paresis of extremities contralateral to the lesion. Specific neurological symptoms and signs such as dysphagia, vertigo, nystagmus, Horner's syndrome, ipsilateral cerebellar ataxia, and contralateral superficial sensory impairment were seen in patients with dorsolateral infarcts of the brain stem. It is hypothesised that the facial CBT descends at the ventromedial lower pons, near the corticospinal tract, mainly to the level of the upper medulla, where the fibres then decussate and ascend in the dorsolateral medulla to synapse in the contralateral facial nucleus.

(F Neurol Neurosurg Psychiatry 2000;69:262-265)
\end{abstract}

Keywords: facial nerve; corticobulbar tract; brain stem; magnetic resonance imaging

The facial nucleus in humans is located dorsolaterally in the caudal pons. ${ }^{12}$ The corticobulbar tract fibres (CBT) that connect the motor cortex with the facial nucleus provide strongly unilateral innervation to the contralateral lower facial muscles and bilateral innervation to the upper facial muscles. ${ }^{1-4}$ Classic symptom localisation has postulated that lesions rostral to the upper mid-pons result in contralateral facial paresis of central type (C-FP), whereas ipsilateral facial paresis of peripheral type (P-FP) ensues from lesions involving the inferolateral part of the pons. ${ }^{15}$ We previously reported on two patients in whom contralateral C-FP resulted from ventromedial medullary infarc- tion, concluding that the facial CBT consists of looping fibres that descend at least to the medullary level and then decussate. ${ }^{6}$ The present study describes our further attempt to clarify the course and distribution of the facial CBT in a larger group of patients with lower brain stem infarction.

\section{Patients and methods}

The present study investigated 70 patients admitted to our department at Aichi Medical University Hospital with acute infarction of the caudal portion of the brain stem between 1989 and 1998. The patients comprised 51 men and 19 women with an age range of 38 to 86 years. Brain MRI was performed within 2 weeks of symptom onset in all patients. For MRI, T1 and T2 weighted images were obtained in both the axial and coronal planes. In the present study, all patients had symptomatic and localised infarctions in the lower brain stem. These were not present in patients with fatal extensive lesion or multiple lesions of the infarct. Patients were classified into the following six groups according to the location and distribution of ischaemic lesions as detected by MRI. Group A (ventromedial involvement at the lower pontine level) comprised seven men and four women with an age range of 58 to 73 years; the lesion was on the right side in six and the left in five. Group B (ventromedial involvement at the upper medullary level) comprised five men and one woman with an age range of 40 to 70; the lesion was on the right in three and the left in three. Group C (ventromedial involvement of the middle to lower medulla) comprised two men and one woman with an age range of 53 to 60 ; the lesion was right in one and left in two. Group D (dorsolateral involvement of the middle to lower medulla) comprised eight men with an age range of 40 to 83; the lesion was right in four and left in four. Group E (dorsolateral involvement of the upper medulla) comprised 20 men and six women with an age range of 38 to 84 ; the lesion was right in 14 and left in 12 . Group F (dorsolateral involvement of the lower pons) comprised nine men and seven women with an age range of 40 to 86 ; the lesion was right in seven and left in nine Attempts were made to determine the rostral and caudal levels of the crossing of facial CBT fibres and to localise the descending and ascending fibres from frequen- 
Table 1 Facial paresis in patients with lower brain stem infarcts

\begin{tabular}{|c|c|c|c|c|}
\hline \multirow[b]{2}{*}{ Site of infarct } & \multicolumn{2}{|c|}{ Presence of $C-F P$} & \multirow[b]{2}{*}{$\begin{array}{l}\text { Presence of P-FP } \\
\text { lesion side }(\%)\end{array}$} & \multirow{2}{*}{$\begin{array}{l}\text { Absence } \\
\text { of FP } \\
(\%)\end{array}$} \\
\hline & $\begin{array}{l}\text { lesion side } \\
(\%)\end{array}$ & $\begin{array}{l}\text { opposed side } \\
(\%)\end{array}$ & & \\
\hline \multicolumn{5}{|l|}{ Ventromedial involvement: } \\
\hline Lower pons $(n=11)$ & $0(0)$ & $11(100)$ & $0(0)$ & $0(0)$ \\
\hline Upper medulla $(\mathrm{n}=6)$ & $0(0)$ & $4(67)$ & $0(0)$ & $2(33)$ \\
\hline Middle to lower medulla $(n=3)$ & $0(0)$ & $0(0)$ & $0(0)$ & $3(100)$ \\
\hline \multicolumn{5}{|l|}{ Dorsolateral involvement: } \\
\hline Middle to lower medulla $(\mathrm{n}=8)$ & $1(13)$ & $0(0)$ & $0(0)$ & $7(87)$ \\
\hline Upper medulla $(n=26)$ & $9(35)$ & $1(4)$ & $0(0)$ & $16(61)$ \\
\hline Lower pons $(n=16)$ & $3(19)$ & $0(0)$ & $11(69)$ & $2(12)$ \\
\hline
\end{tabular}

$\mathrm{C}-\mathrm{FP}=$ central facial paresis; $\mathrm{P}-\mathrm{FP}=$ peripheral facial paresis; $\mathrm{FP}=$ facial paresis.

Table 2 Frequency of major symptoms and signs in patients with lower brain stem infarcts

\begin{tabular}{|c|c|c|c|c|c|c|}
\hline Symptom and signs & $\begin{array}{l}\operatorname{group} A \\
(n=11) \\
(\%)\end{array}$ & $\begin{array}{l}\operatorname{group} B \\
(n=6) \\
(\%)\end{array}$ & $\begin{array}{l}\underset{(n=3)}{\operatorname{group}} C \\
(\%)\end{array}$ & $\begin{array}{l}\underset{(n=8)}{\operatorname{group} D} \\
(\%)\end{array}$ & $\begin{array}{l}\operatorname{group} E \\
(n=26) \\
(\%)\end{array}$ & $\begin{array}{l}\operatorname{group} F \\
(n=16) \\
(\%)\end{array}$ \\
\hline \multicolumn{7}{|l|}{ Symptoms: } \\
\hline Dysphagia & $0(0)$ & $0(0)$ & $0(0)$ & $4(50)$ & $14(54)$ & $7(44)$ \\
\hline Vertigo & $0(0)$ & $0(0)$ & $0(0)$ & $4(50)$ & $18(69)$ & $7(44)$ \\
\hline Hiccups & $0(0)$ & $0(0)$ & $0(0)$ & $2(25)$ & $6(23)$ & $1(6)$ \\
\hline Hoarseness & $0(0)$ & $0(0)$ & $0(0)$ & $5(63)$ & $12(46)$ & $4(25)$ \\
\hline \multicolumn{7}{|l|}{ Signs: } \\
\hline Nystagmus & $0(0)$ & $0(0)$ & $0(0)$ & $8(100)$ & $20(77)$ & $12(75)$ \\
\hline Soft palate paresis & $0(0)$ & $0(0)$ & $0(0)$ & $6(75)$ & $18(69)$ & $0(0)$ \\
\hline Horner's syndrome & $0(0)$ & $0(0)$ & $0(0)$ & $6(75)$ & $19(73)$ & $7(44)$ \\
\hline Sensory impairment of face & $0(0)$ & $0(0)$ & $0(0)$ & $7(88)$ & $15(58)$ & $9(56)$ \\
\hline Ipsilateral cerebellar ataxia & $0(0)$ & $0(0)$ & $0(0)$ & $7(88)$ & $22(85)$ & $11(69)$ \\
\hline $\begin{array}{l}\text { Contralateral limb and } \\
\text { truncal superficial sensory } \\
\text { impairment }\end{array}$ & $0(0)$ & $0(0)$ & $0(0)$ & $8(100)$ & $19(73)$ & $8(50)$ \\
\hline $\begin{array}{l}\text { Contralateral limb and } \\
\text { truncal deep sensory }\end{array}$ & & & & & & \\
\hline impairment & $2(18)$ & $2(33)$ & $0(0)$ & $0(0)$ & $0(0)$ & $0(0)$ \\
\hline Contralateral limb paresis & $11(100)$ & $6(100)$ & $3(100)$ & $0(0)$ & $3(12)$ & $0(0)$ \\
\hline
\end{tabular}

cies of occurrence of C-FP or P-FP and other brain stem signs. Furthermore, to elucidate the course and location of facial CBT in axial sections of the brain stem, a comparative analysis was conducted of major neurological symptoms and signs among the six groups.

\section{Results}

FREQUENCY OF OCCURRENCE OF C-FP AND P-FP (TABLE 1)

A C-FP occurred in 29 of the total 70 patients. The C-FP seen in these patients was relatively mild, and recovery was almost complete within 1 to 2 months of onset. All 11 patients of group A (ventromedial involvement of lower pons) showed C-FP on the side opposite to the lesion. Among the six patients of group B (ventromedial involvement of upper medulla), four patients $(67 \%)$ showed C-FP on the side opposite to the lesion. The remaining two patients $(33 \%)$ showed no evidence of C-FP. In group C (ventromedial involvement at the middle to lower medulla), C-FP was not present in any of the three patients.

Of the eight patients in group D (dorsolateral involvement of the middle to lower medulla), only one (13\%) developed C-FP on the side of the lesion. A C-FP was also clinically present in 10 of the 26 patients in group E (dorsolateral involvement of the upper medulla), and C-FP of the nine patients (35\%) was on the side of the lesion and one patient (4\%) on the opposite side. Of the 16 patients in group $\mathrm{F}$ (dorsolateral involvement of the lower pons), P-FP occurred on the side of the lesion in 11 patients $(69 \%)$, and C-FP in another three $(19 \%)$.
FREQUENCY OF MAJOR SYMPTOMS AND SIGNS IN PATIENTS WITH LOWER BRAIN STEM INFARCTS (TABLE 2)

In the three groups with ventromedial involvement of the lower brain stem (A, B, C), hemiplegia on the side opposite to the lesion was a common sign. None of the patients in these three groups showed symptoms or signs which were seen the patients with involvement of the dorsolateral part at the level of lower brain stem. Two patients (18\%) of group A and two $(33 \%)$ of group B had deep sensory impairment of the limbs and trunk on the opposite side.

In the remaining three groups with dorsolateral involvement of the lower brain stem $(\mathrm{D}, \mathrm{E}$, $\mathrm{F})$, contralateral limb paresis occurred in only three patients $(12 \%)$ belonging to group E. In patients with these dorsolateral infarcts, a wide variety of symptoms and signs of involvement such as dysphagia, vertigo, hiccups, hoarseness, nystagmus, paralysis of the soft palate, Horner's syndrome, facial sensory impairment, ipsilateral cerebellar ataxia, and contralateral superficial sensory impairment of limb and trunk were present.

\section{Discussion}

Some CBT fibres in humans are thought to leave the corticospinal tract (CST) in the brain stem, ${ }^{7-11}$ with a portion of them descending in the medial lemniscus as an aberrant pyramidal tract, although their precise topographic anatomy is not clear. ${ }^{3}{ }^{10}$ To explain C-FP from lesions caudal to the facial nucleus, damage to the aberrant pyramidal tract has been postulated, including involvement of the classic Pick's bundle, ${ }^{12-15}$ which reverses course in the pyramidal decussation and ascends in the CST to connect with the motor nuclei of some cranial nerves. However, whether or not the facial nucleus actually receives such CBT fibres has not been determined. ${ }^{3} 1617$

Currier $^{18}$ has hypothesised that facial CBT fibres leave the pyramidal tract at the pontomedullary junction and descend caudally to at least the middle medullary levels before most of them cross to the opposite facial nucleus. Interruption of these fibres by infarction at a predecussation level has been postulated to result in a contralateral C-FP. Cavazos et $a l^{19}$ have described some fibres of the facial CBT as descending ipsilaterally, making a loop as caudally as the upper medulla before decussating and ascending to the contralateral facial nucleus. Our results indicate that C-FP occurred more often in patients with a lesion extending from the lower pons to the upper medulla than in those with a lesion in the middle to lower medulla, regardless of whether the lesion was located ventromedially or dorsolaterally. Kim et $a l^{20}$ have also reported that, in patients with lateral medullary infarction, C-FP was seen more often with high than middle to low medullary lesions.

Our present findings suggest that the facial CBT descends at least to the level of the upper medulla, where the fibres cross the midline, even though their specific topographic anatomy may vary from one person to another (figure A). The 

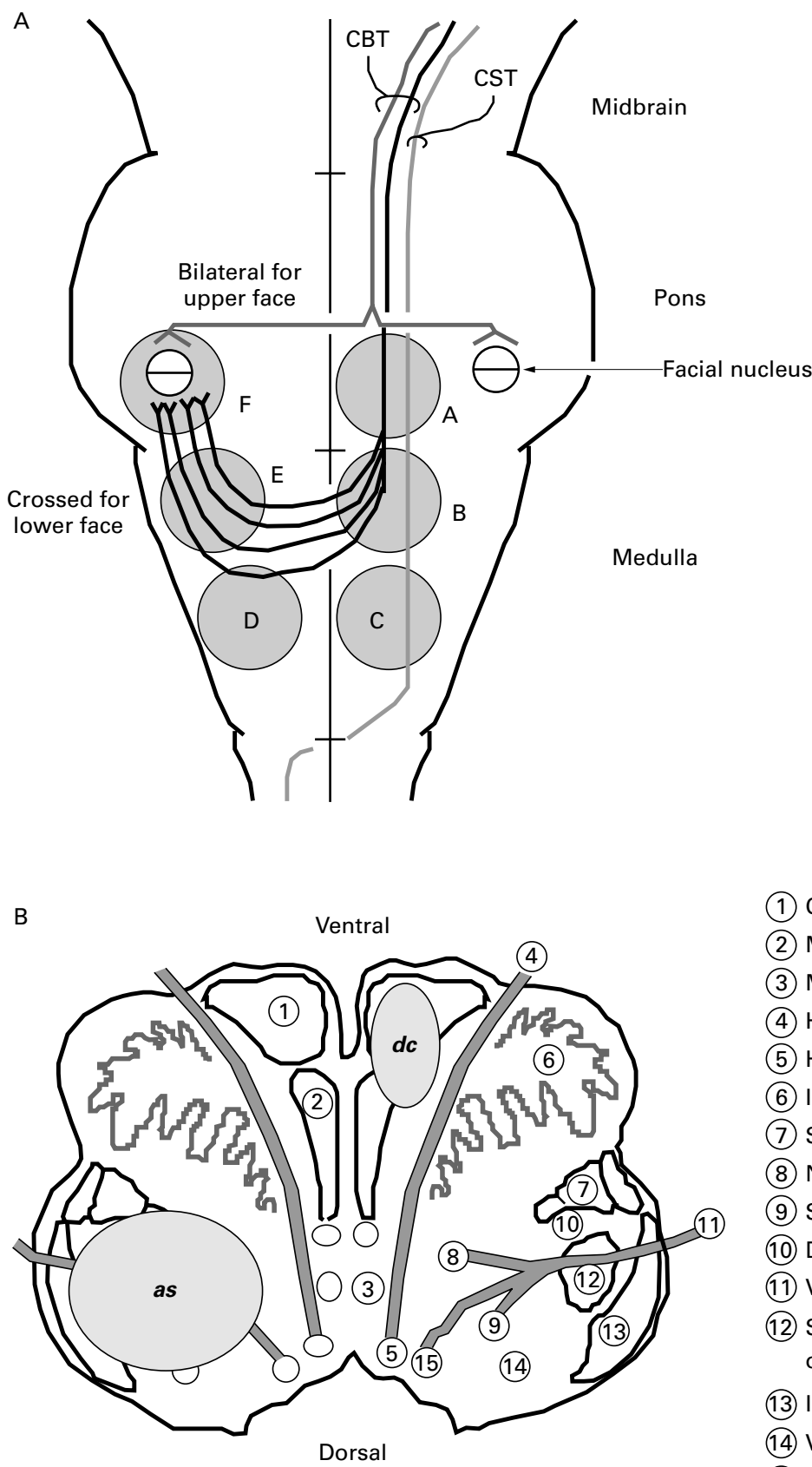

(1) Corticospinal tract

(2) Medial lemniscus

(3) Medial longitudinal fasciculus

(4) Hypoglossal nerve (XII)

(5) Hypoglossal nucleus

(6) Inferior olivary nucleus

(7) Spinothalamic tract

(8) Nucleus ambiguus

(9) Solitary nucleus

(10) Descending sympathetic tract

(11) Vagus nerve $(X)$

(12) Spinal tract and nucleus of trigeminal nerve $(\mathrm{V})$

(13) Inferior cerebellar peduncle

(14) Vestibular nucleus

(15) Dorsal nucleus of vagus

(A) Schematic diagram of pathways of the facial corticobulbar tract (CBT). The corticospinal tract is designated CST. The six grey areas show the locations of lower brain stem infarctions in the groups studied, $A$ to $F$ (B) Facial corticobulbar tract $(C B T)$ fibre distribution is shown in the upper medulla: $d c=$ descending fibres; as=ascending fibres.

facial CBT, then, could be represented as looping fibres, most of which decussate in the upper medulla. This schema is an alternative to placing these CBT fibres in the aberrant pyramidal tract, which reverses course in the lower medulla to ascend from the pyramidal decussation. Jenny et $a l^{4}$ have reported that descending CBT fibres innervated the lower facial motor nuclear region bilaterally in the monkey, although with contralateral predominance. Therefore, nondecussating CBT fibres supplying the ipsilateral lower facial nucleus may be present in humans. ${ }^{41}$ On the basis of locations of facial CBT seen in axial sections, we would argue that these CBT fibres descend near the CST, mostly to the upper medulla, where they decussate and ascend in the dorsolateral medulla to connect with the facial nucleus (figure A and B). On the other hand, as C-FP resulting from involvement of ascending pathways occurred less often than C-FP from involvement of descending pathways; these ascending pathways may be widely dispersed in the dorsolateral medulla rather than representing a discrete bundle.

Additional clinicoradiological, clinicopathological, and neuroanatomical studies should help to further clarify the courses of central pathways, including the CBT, in humans.

This work was supported by a research grant for longevity sciences (110-05) from the Ministry of Health and Welfare. 
1 Patten J. The brain stem. In: Patten J, ed. Neurological differential diagnosis, 2nd ed. London: Springer, 1996:162-77.

2 Parent A. Pons. In: Parent A, ed Carpenter's human neuroanatomy. 9th ed. Baltimore: Williams and Wilkins, 1996:469-526

3 Kuypers HGJM. Corticobulbar connexions to the pons and lower brain-stem in man. An anatomical study. Brain 1958, 81:364-88.

4 Jenny AB, Saper CB. Organization of the facial nucleus and corticofacial projection in the monkey: a reconsideration of the upper motor neuron facial palsy. Neurology 1987;37 930-9.

5 Adams RD, Victor M. Motor paralysis. In: Adams RD, Victor M, Ropper AH, eds. Principles of neurology, 6th ed. New York: McGraw-Hill, 1997:45-63.

6 Terao S, Takatsu S, Izumi M, et al. Central facial weakness due to medial medullary infarction: the course of facial due to 391-3.

7 Crosby EC, Humphrey T, Lauer EW. Correlative anatomy of the nervous system. New York: Macmillan, 1962:262-4.

8 Huang CY, Woo E, Yu YL, et al. Lacunar syndromes due to brainstem infarct and haemorrhage. $f$ Neurol Neurosurg Psychiatry 1988;51:509-15.

9 Kawai M, Iwata M, Mannen T, et al. Localization of the corticobulbar tract in pons. Rinsho Shinkeigaku 1988;28:897901

10 Yamamoto T, Yamasaki M, Imai T. Retrograde pyramidal tract degeneration in a patient with cervical haematomyelia. F Neurol Neurosurg Psychiatry 1989;52:382-6.

11 Hopf HC, Tettenborn B, Kramer G. Pontine supranuclear facial palsy. Stroke 1990;21:1754-7.
12 Pick A. Ueber ein abnormes Faserbundel in der menschlichen Medulla oblongata. Arch Psychiatr Nervenkr 1890;21:636-40.

13 Barnes S. Degenerations in hemiplegia: with special reference to a ventrolateral pyramidal tract, the accessory fillet and Pick's bundle. Brain 1901;24:463-501.

14 Nyberg-Hansen R, Rinvik E. Some comments on the pyramidal tract, with special reference to its individual variations in man. Acta Neurol Scand 1963;39:1-30.

15 Puvanendran K, Wong PK, Ransome GA. Syndrome of Pejerine's Fourth Reich. Acta Neurol Scand 1978;57:34953.

16 Fisher CM, Karnes WE, Kubik CS. Lateral medullary infarction: the pattern of vascular occlusion. $f$ Neuropathol Exp Neurol 1961;20:323-79.

7 Sacco RL, Freddo L, Bello JA, et al. Wallenberg's lateral medullary syndrome. Clinical-magnetic resonance imaging correlations. Arch Neurol 1993;50:609-14.

18 Currier RD. The medial medullary syndrome. $f$ Univ Mich Med Cent 1976;42:96-104.

19 Cavazos JE, Bulsara K, Caress J, et al. Pure motor hemiplegia including the face induced by an infarct of the medullary pyramid. Clin Neurol Neurosurg 1996;98:21-3.

$20 \mathrm{Kim}$ JS, Lee JH, Suh DC, et al. Spectrum of lateral medullary syndrome. Correlation between clinical findings and magnetic resonance imaging in 33 subjects. Stroke 1994;25: 1405-10

21 Yamana T, Hasegawa Y, Dei R, et al. Ipsilateral central-type facial palsy and contralateral hemiparesis associated with unilateral medial medullary infarction: a case report. Rinsho Shinkeigaku 1998;38:750-3. 